\title{
Additional effects of the cervical length measurement in women with preterm contractions: a systematic review
}

\author{
Jolande Y. Vis • Rosanna A. Kuin • \\ William A. Grobman · Ben Willem J. Mol • \\ Patrick M. M. Bossuyt $\cdot$ Brent C. Opmeer
}

Received: 13 October 2010/Accepted: 24 February 2011/Published online: 12 April 2011

(C) The Author(s) 2011. This article is published with open access at Springerlink.com

\begin{abstract}
Purpose Transvaginal cervical length measurement in women with symptoms of preterm labor has been used to decide if treatment is necessary. Cervical length measurement may also have additional effects on patients, such as providing reassurance, although the evidence to support this is unclear. We explored and summarized to what extent additional effects of cervical length measurement in women with threatened preterm labor have been reported in the clinical literature and what the magnitude of these effects was.

Methods We performed a systematic review of the literature to identify articles reporting on cervical length measurements in women with symptoms of preterm labor. We assessed whether these articles reported patient outcomes other than preterm delivery.

Results The electronic and hand search resulted in 764 articles, of which 172 met initial criteria for further eligibility assessment. We found 12 articles that reported additional effects of cervical length measurement in symptomatic women, such as the reassurance or the sensory consequences related to the transvaginal procedure. None of the articles quantified such additional effects.
\end{abstract}

J. Y. Vis $(\bowtie) \cdot$ R. A. Kuin - B. W. J. Mol

Department of Obstetrics and Gynecology,

Academic Medical Center, Amsterdam, The Netherlands

e-mail: j.y.vis@amc.nl

J. Y. Vis · P. M. M. Bossuyt · B. C. Opmeer

Department of Clinical Epidemiology, Biostatistics

and Bioinformatics, Academic Medical Center,

Amsterdam, The Netherlands

W. A. Grobman

Department of Obstetrics and Gynecology,

Northwestern University, Chicago, USA
Conclusions There appears to be a gap between the presumed effects of cervical length measurement on patient outcomes, such as patients' reassurance, and the actual assessment of these effects during test evaluations. We suggest that future evaluations of prognostic preterm labor tests include a comprehensive assessment of patient outcomes.

Keywords Cervical length - Preterm labor - Diagnostic test $\cdot$ Methodology $\cdot$ Reassurance $\cdot$ Patient perspective

\section{Introduction}

In pregnant women with symptoms of preterm labor, prediction of imminent preterm delivery is of utmost importance. This information can be used to decide on tocolytics and administration of corticosteroids, and allows timely transfer to perinatal centers. Whether cervical length measurement provides benefit for these women has been a recurrent topic of study. In general, women with a short cervix are at higher risk for preterm delivery than women with a long cervix. If the cervix is of sufficient length, the chance of imminent preterm delivery is low, and hospitalization or therapy of women otherwise considered at-risk may be avoided. Consequently, a number of studies have evaluated the prognostic accuracy of this test with respect to predicting preterm delivery [1].

As women with preterm contractions are often worried that these contractions represent actual preterm labor, physicians also may use cervical length measurement to reassure pregnant women whose cervix is not shortened. Since the image of cervical ultrasound is visually illustrative to patients, this test is believed to enhance reassurance. 
It is has been shown for a variety of tests that their results may have additional effects on patients other than guiding clinical management decisions. [2] These additional effects may also be an important reason for physicians to order a test [3]. However, it is unclear to what extent reassurance and other psychological effects on patients have been documented in evaluations of cervical length measurement. It is possible that the intended effect of reassuring worried women is not achieved in clinical practice, and that cervical length measurement actually induces anxiety rather than relieves uncertainty [4].

We have performed a systematic review of the literature to explore and summarize to what extent effects beyond the prognostic accuracy or therapeutic ramifications of cervical length measurement in women with preterm contractions have been reported, and to obtain the estimates of the magnitude of these effects.

\section{Methods}

We performed an electronic search on PubMed using the following search strategy: (cervical length measurement [Mesh] OR (cervi* [tiab] AND (length [tiab] OR ultrasonography [Mesh] OR measurem*[tiab] OR ultrasound[tiab] OR echo[tiab])) AND ((preterm* [tiab] OR premat* [tiab]) AND (parturition [Mesh] OR parturit* [tiab] OR birth [tiab] OR labor [tiab] OR labour [tiab] OR newborn*[tiab] OR infant[tiab])) OR obstetric labor, premature [Mesh] OR premature birth [Mesh] OR infant, premature [Mesh]). In addition, we searched the reference lists of identified articles for additional studies. We applied no exclusion criteria, and thus all study designs and languages were eligible for inclusion.

Article selection was performed independently by two authors (JV and RK). The articles resulting from the electronic search initially were screened based on titles and abstracts. All articles that evaluated cervical length measurement in women with threatened preterm contractions were selected for further evaluation and full-text assessments were made. Discrepancies in article selection were resolved by achieving consensus through discussions.

All articles selected for full-text assessment were studied in detail. For the final analysis we included all articles that reported or mentioned any additional effects of the transvaginal cervical length measurement. Characteristics of the articles (e.g. type of study design, year of publication) were extracted. Further, we evaluated the type of patient outcome that was reported, whether this additional effect was measured or merely mentioned, whether these measurements were quantitative or qualitative, and, if they were quantitative, what the magnitude of the effect was.

\section{Results}

The electronic search yielded 756 articles. The additional hand search resulted in eight additional articles being identified. Of these 764 articles, 194 (25\%) articles were selected based on the title and abstract for full-text assessment. However, 22 articles could not be included because no full text was available in The Netherlands. Nevertheless, the abstracts of these 22 articles did not discuss any additional effects of the transvaginal cervical length measurement.

Of the 172 articles that could be studied, 97 reported on the accuracy of preterm labor tests, of which 70 in particular about cervical length measurement in women with preterm labor. We found 25 articles that described additional effects of preterm labor tests. Thirteen of these articles were not related to transvaginal cervical length measurement: four described additional effects of fetal fibronectin tests [4-7] of which one article measured maternal anxiety by questionnaires [5], eight described additional psychosocial effects in women without symptoms of preterm labor [8-15] of which most focused on the acceptability of the transvaginal procedure, and one paper described additional psychosocial effects related to translabial, but not transvaginal, ultrasonography [16] (Table 1).Thus, 12 articles described additional effects of the cervical length measurement in women with threatened preterm labor and were eligible for further analysis (Table 2, Fig. 1).

The provision of reassurance as an additional consequence of the cervical length measurement in women with threatened preterm labor was described in one beforeand-after-measurement study by Sanin-Blair et al. [17]. In the discussion section of the article the authors suggested that cervical length measurement might give more reassurance to both women with symptoms of preterm labor and their physicians in comparison to digital examinations due to it numerical result. However, no data were provided to support this concept. One cohort study by Holst et al. [18] noted in the discussion section that false positive cervical length measurements could lead to 'psychological costs', although did not provide any further reference or specification on what these costs entailed or how they should be measured.

More frequently, additional sensory effects of the procedure of transvaginal ultrasound were discussed, although these effects were not related to the actual result of the cervical length measurement. The magnitude of this additional effect was reported in one descriptive series [19]. Based on a questionnaire survey in pregnant women at 23 weeks of gestation, the authors stated that only $2 \%$ of women reported pain or severe discomfort during the transvaginal ultrasound procedure [9]. Nine other articles 
Table 1 Excluded articles that described additional effects of the cervical length measurement or other tests that can predict preterm delivery, but not of the transvaginal cervical length measurement in women with preterm contractions

\begin{tabular}{|c|c|c|}
\hline Author, year & Study design & Citations (Clustered per additional effect) \\
\hline \multicolumn{3}{|l|}{ Acceptance } \\
\hline $\begin{array}{l}\text { Berghella } 2003 \\
{[16]}\end{array}$ & Descriptive review & "It [translabial ultrasound] is well accepted by patients" \\
\hline $\begin{array}{l}\text { Clement } 2003 \\
\text { [9] }\end{array}$ & $\begin{array}{l}\text { Prospective cohort, } \\
\quad N=922\end{array}$ & $\begin{array}{l}\text { "Conclusions: Antenatal transvaginal ultrasound for assessing the risk of preterm delivery is an } \\
\text { acceptable procedure for the majority of women. A significant minority declined the scan. The } \\
\text { procedure has some psychological sequelae for some women." [study in asymptomatic women, all } \\
\text { at } 23 \text { weeks of gestation] }\end{array}$ \\
\hline $\begin{array}{l}\text { Hertzberg } 2001 \\
{[11]}\end{array}$ & $\begin{array}{l}\text { Prospective cohort, } \\
\quad N=64\end{array}$ & $\begin{array}{l}\text { "maneuvers [during endovaginal ultrasonography] can be uncomfortable for the patient" (...) "All } \\
\text { patients tolerated the perineal scanning procedure well, without significant physical discomfort, and } \\
\text { the procedure was uniformly accepted by our population of patients". [study in asymptomatic } \\
\text { women] }\end{array}$ \\
\hline Carr $2000[8]$ & $\begin{array}{l}\text { Prospective cohort, } \\
\quad N=84\end{array}$ & $\begin{array}{l}\text { "Translabial ultrasonography should still be considered an imaging option, particularly when vaginal } \\
\text { instrumentation is unacceptable or tolerated poorly by the patient." [study in asymptomatic women] }\end{array}$ \\
\hline Heath 1998 [10] & $\begin{array}{l}\text { Prospective cohort, } \\
\quad N=2,702\end{array}$ & $\begin{array}{l}\text { "In addition, } 100 \text { women were asked to complete a questionnaire aimed to assess the degree of } \\
\text { discomfort pain or embarrassment caused by the scan."-_-Conclusions: Transvaginal sonography } \\
\text { measurement of cervical length is (...) associated with a minimal degree of discomfort to patients." } \\
\text { [study in asymptomatic women, all at } 23 \text { weeks of gestation] }\end{array}$ \\
\hline Sonek $1990[13]$ & $\begin{array}{l}\text { Prospective cohort, } \\
\quad N=201\end{array}$ & $\begin{array}{l}\text { "The operator must have considerable experience, and occasionally the extensive manipulation with } \\
\text { the vaginal probe causes discomfort" [study in asymptomatic patients] }\end{array}$ \\
\hline \multicolumn{3}{|l|}{ Anxiety } \\
\hline $\begin{array}{l}\text { Chamdiramani } \\
2006[4]\end{array}$ & Descriptive review & $\begin{array}{l}\text { "In asymptomatic women, fFN in patients at high risk of PTD based on history or cervical change s a } \\
\text { good predictor of PTD under } 30 \text { weeks. This associated, however, with increased levels of anxiety } \\
\text { (ref: Shennan 2005)". }\end{array}$ \\
\hline $\begin{array}{l}\text { Shennan } 2005 \\
{[5]}\end{array}$ & $\begin{array}{l}\text { Prospective cohort, } \\
\quad N=146\end{array}$ & $\begin{array}{l}\text { "Main outcome measures: maternal anxiety and efficacy of the } 24 \text {-week fetal fibronectin test to } \\
\text { predict delivery before } 30,34 \text { and } 37 \text { weeks of gestation."- - Conclusion: Fetal fibronectin (...) } \\
\text { was associated with high levels of anxiety." }\end{array}$ \\
\hline \multicolumn{3}{|l|}{ Preparation } \\
\hline Wyatt 2006 [7] & Descriptive review & $\begin{array}{l}\text { "The negative predictive value [of the fibronectin test] is very important not only clinically, but on a } \\
\text { personal level as well. A negative result allows a pregnant woman to function normally and avoid } \\
\text { bed rest, hospitalization, medication, and the anxiety associated with the possibility of a PTD. } \\
\text { A positive result allows the patient to prepare mentally for the potential risk, albeit small, of having } \\
\text { a PTD and provides an important window for education." }\end{array}$ \\
\hline \multicolumn{3}{|l|}{ Reassurance } \\
\hline Vis 2009 [6] & Study protocol & "testing for fFN may $(\ldots)$ decrease stress and anxiety for the families." \\
\hline $\begin{array}{l}\text { Leitich } 2005 \\
{[12]}\end{array}$ & Descriptive review & $\begin{array}{l}\text { "Negative test results [of fetal fibronectin and cervical length by transvaginal ultrasonography] would } \\
\text { be valuable in reassuring both women [at high risk for preterm birth, such as women with previous } \\
\text { preterm births or late miscarriages] and care providers to avoid unnecessary interventions." }\end{array}$ \\
\hline $\begin{array}{l}\text { Vidaeff } 2006 \\
\text { [14] }\end{array}$ & Descriptive review & $\begin{array}{l}\text { "According to the American College of Obstetricians and Gynecologists (ACOG) the benefit of such } \\
\text { testing [cervical length measurement] is more to identify those high risk patients by historic criteria } \\
\text { who actually are at minimal risk for PTD during the index pregnancy, for reassurance and } \\
\text { avoidance of unnecessary surveillance or interventions. }\end{array}$ \\
\hline $\begin{array}{l}\text { Volumenie } 2004 \\
{[15]}\end{array}$ & $\begin{array}{l}\text { Prospective cohort, } \\
\quad N=59\end{array}$ & $\begin{array}{l}\text { "Ultrasonography is undoubtedly superior to digital examination in bringing to the fore cervical } \\
\text { shortening or funneling before the external os is open, and thus is of maximal interest in these } \\
\text { situations, either to identify a high risk group or conversely to reassure a patient with a previous } \\
\text { preterm delivery if the cervix remains long during the following pregnancy." }\end{array}$ \\
\hline
\end{tabular}

mentioned patients' acceptance of transvaginal ultrasound procedures, without quantifying this acceptance [20-27]. Of these articles, one cohort study reported that transvaginal cervical length measurement was better tolerated than digital exams [27]. This statement was supported by a remark in a letter (specifically an author's reply to a letter to the editor) [24] and by a qualitative review [20] referring to a study that assessed pain scores of transvaginal ultrasound and digital exams in women undergoing induction of labor [28]. In addition, three review papers [23, 25, 26] and one cohort study [22] stated that transvaginal cervical length measurement was acceptable for patients. Three of these articles referred to questionnaire surveys that had assessed the acceptability of transvaginal ultrasound in the 
Table 2 Included articles with citations about additional effects of cervical length measurements

\begin{tabular}{|c|c|c|}
\hline Author, year & Study design & Citations (Clustered per additional effect) \\
\hline \multicolumn{3}{|l|}{ Acceptance } \\
\hline $\begin{array}{l}\text { Chao } 2008 \\
{[20]}\end{array}$ & Descriptive review & $\begin{array}{l}\text { "The examination [transvaginal cervical ultrasound] is tolerable to pregnant women. (Tan, } \\
2007[28]) \text { " }\end{array}$ \\
\hline $\begin{array}{l}\text { Berghella } \\
2005[19]\end{array}$ & Descriptive review & $\begin{array}{l}\text { "Only minimal discomfort was reported by women undergoing TVU, with pain or severe discomfort } \\
\text { in less than } 2 \% \text { of women. Over } 99 \% \text { of women agreed to have a similar procedure in the future. } \\
\text { (Clement, 2003)" }\end{array}$ \\
\hline $\begin{array}{l}\text { Gomez } 2005 \\
{[22]}\end{array}$ & $\begin{array}{l}\text { Prospective cohort, } \\
\quad N=215\end{array}$ & "Previous studies indicate that cervical sonography is acceptable to patients (Heath 1998)" \\
\hline $\begin{array}{l}\text { Rozenberg } \\
2005[24]\end{array}$ & Author reply & "Ultrasound examination is easier and less unpleasant than cervical digital examination." \\
\hline $\begin{array}{l}\text { Shennan } 2004 \\
{[25]}\end{array}$ & Descriptive review & $\begin{array}{l}\text { "Women find the procedure [transvaginal ultrasound] very acceptable in the vast majority of cases } \\
\text { (Clement 2003)." }\end{array}$ \\
\hline $\begin{array}{l}\text { Doyle } 2004 \\
{[21]}\end{array}$ & Descriptive review & $\begin{array}{l}\text { "Patient and examiner reticence to perform transvaginal ultrasound has led to examination using a } \\
\text { translabial or transperineal approach." }\end{array}$ \\
\hline $\begin{array}{l}\text { Owen } 2003 \\
{[23]}\end{array}$ & Descriptive review & $\begin{array}{l}\text { "advantages in endovaginal ultrasonographic cervical assessment }(\ldots) \text { and patient acceptance have } \\
\text { overcome many of the limitations of both digital examinations and earlier transabdominal methods } \\
\text { of cervical ultrasonography." }\end{array}$ \\
\hline $\begin{array}{l}\text { Vendittelli } \\
2001[27]\end{array}$ & $\begin{array}{l}\text { Prospective cohort, } \\
\quad N=200\end{array}$ & $\begin{array}{l}\text { "Another incitement in using transvaginal ultrasonography is that it is performed with relatively thin } \\
\text { probes which, in our experience and by some authors, is usually better tolerated by women than } \\
\text { manual examinations." }\end{array}$ \\
\hline \multicolumn{3}{|c|}{ Psychological/economical } \\
\hline $\begin{array}{l}\text { Holst } 2006 \\
{[18]}\end{array}$ & $\begin{array}{l}\text { Prospective cohort, } \\
\quad N=87\end{array}$ & $\begin{array}{l}\text { [consequence false positive cervical length measurement] "at considerable psychological and } \\
\text { economic costs for the families involved." }\end{array}$ \\
\hline \multicolumn{3}{|l|}{ Reassurance } \\
\hline $\begin{array}{l}\text { Sanin-Blair } \\
2004[17]\end{array}$ & $\begin{array}{l}\text { Before-and-after study, } \\
\quad N=294\end{array}$ & $\begin{array}{l}\text { "A numerical value [of the cervical length by ultrasound in comparison to digital examination] is } \\
\text { easier to compare and/or monitor over time, and this can contribute to reassure patients and } \\
\text { physicians, further facilitating the decision of hospital discharge." }\end{array}$ \\
\hline \multicolumn{3}{|c|}{ Patients' preferences } \\
\hline $\begin{array}{l}\text { Goffinet } 2001 \\
{[30]}\end{array}$ & Descriptive review & $\begin{array}{l}\text { "both physicians and patients are more likely [in case of threatened preterm labor] than in a general } \\
\text { population to want more complicated and more expensive examination, on condition nonetheless } \\
\text { that they are more efficacious". }\end{array}$ \\
\hline \multicolumn{3}{|l|}{ Satisfaction } \\
\hline $\begin{array}{l}\text { Vendittelli } \\
2000[26]\end{array}$ & Systematic review & $\begin{array}{l}\text { "it [ultrasonography of the cervix] could reduce hospital stays of women undergoing preterm labour } \\
\text { and so decrease hospital expenditure and make patients more satisfied with the health care } \\
\text { system. (...) Transvaginal ultrasonography is also well accepted by pregnant women } \\
\text { (Braithwaite } 2008 \text { [29])" }\end{array}$ \\
\hline
\end{tabular}

first or second trimester of pregnancy [9, 10, 13, 29]. In contrast, one qualitative review noted patients' reticence to have transvaginal ultrasound performed, but did not provide further details [21].

One descriptive review mentioned that the performance of cervical length measurements could enhance patient satisfaction with the health care system, without specifying a mechanism for or quantifying this enhancement [26]. One cohort study stated that, in general, the false positive results of the cervical length measurement could lead to financial costs of families, although no data were provided to demonstrate this possibility [18]. Finally, one systematic review stated that patients (and physicians) would prefer any extra test that would enhance efficacy, without offering further explanation what that efficacy entailed [30].

\section{Discussion}

This systematic review shows that test evaluations of cervical length measurements in women with threatened preterm labor have not yet integrated patient-centered outcomes beyond preterm delivery. We did not find a single study that had measured the psychosocial effects of performing a cervical length measurement in women with symptoms of preterm labor. In contrast, such additional effects were considered relevant by several authors, who often referred to them in the discussion section of their articles.

This review illustrates that empirical evidence about an expected reassuring effect of cervical length measurement in women with threatened preterm labor is lacking. Our analysis does not allow us to make statements whether this type of evaluation was done in studies of other prognostic 
Fig. 1 Flow diagram of included and excluded articles. $C L$ transvaginal cervical length measurement, $P T L$ preterm labor

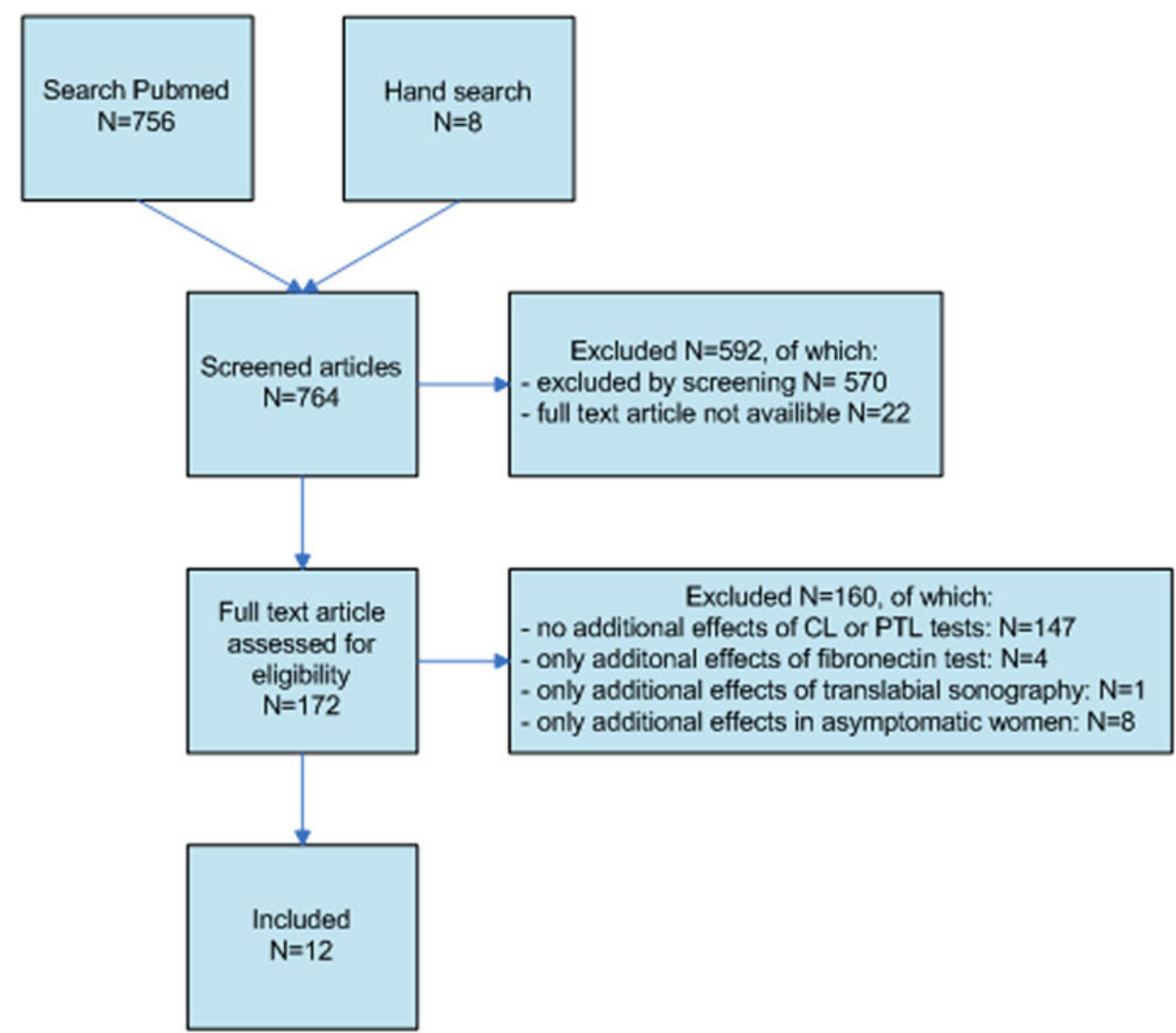

tests associated with preterm labor, as we did not include studies of other prognostic preterm labor medical tests, such as the fetal fibronectin test. In addition, we also did not include articles that show additional effects of the cervical length measurement in women without symptoms of preterm labor.

Although we found 70 articles that reported on studies of the accuracy of cervical length measurement in women with threatened preterm labor, we did not find any obstetrical research that documented other effects of the cervical length measurement in symptomatic women. We hope that future researchers recognize that such additional effects may be of great importance for patients as well, and that they should be assessed and quantified. For instance, patients may be reassured if they can see for themselves that the cervix is still long. In addition, this may also affect medical outcomes if cervical length measurement in itself influences potential risk factors for preterm labor, such as psychological stress [31]. For example, a short cervix may be seen in a woman who will not have a preterm delivery, but increase anxiety. Or it is possible that undesired behaviors (e.g. smoking) associated with preterm birth are reinforced by reassuring results. Until these additional effects on patient outcomes are actually measured, their existence is at best based on anecdotal evidence and the magnitude of these effects remains unknown. Therefore, it is still unclear if such presumed additional effects have the potential to influence test recommendations about cervical length measurements.

In summary, we found that multiple authors have pointed to the potential of cervical length measurements to affect a range of patient outcomes, such as reassurance and anxiety, but these effects have not yet been measured. We suggest that such additional effects of medical testing require formal evaluation before statements about their existence are made, and that recommendations about testing and test strategies should be based on comprehensive evaluations of the effects of testing on patients. Correspondingly, future studies evaluating transvaginal cervical length measurement for preterm labor should include a more complete assessment of patient outcomes.

Acknowledgments This study is funded by ZonMw, The Netherlands Organisation for Health Research and Development, dossier number 80-82325-98-8011. Website: http://www.zonmw.nl.

\section{Conflict of interest None.}

Open Access This article is distributed under the terms of the Creative Commons Attribution Noncommercial License which permits any noncommercial use, distribution, and reproduction in any medium, provided the original author(s) and source are credited. 


\section{References}

1. Sotiriadis A, Papatheodorou S, Kavvadias A, Makrydimas G (2010) Transvaginal cervical length measurement for prediction of preterm birth in women with threatened preterm labor: a metaanalysis. Ultrasound Obstet Gynecol 35:54-64

2. Bossuyt PM, McCaffery K (2009) Additional patient outcomes and pathways in evaluations of testing. Med Decis Making 29:E30-E38

3. Whiting P, Toerien M, de Salis I, Sterne JA, Dieppe P, Egger M, Fahey T (2007) A review identifies and classifies reasons for ordering diagnostic tests. J Clin Epidemiol 60:981-989

4. Chandiramani M, Shennan A (2006) Preterm labour: update on prediction and prevention strategies. Curr Opin Obstet Gynecol 18:618-624

5. Shennan A, Jones G, Hawken J, Crawshaw S, Judah J, Senior V, Marteau T, Chinn S, Poston L (2005) Fetal fibronectin test predicts delivery before 30 weeks of gestation in high risk women, but increases anxiety. BJOG 112:293-298

6. Vis JY, Wilms FF, Oudijk MA, Porath MM, Scheepers HC, Bloemenkamp KW, Bolte AC, Cornette J, Derks JB, Duvekot JJ, van EJ, Kwee A, Opmeer BC, van Pampus MG, Lotgering FK, Scherjon SA, Sollie KM, Spaanderman ME, Willekes C, van der Post JA, Mol BW (2009) Cost-effectiveness of fibronectin testing in a triage in women with threatened preterm labor: alleviation of pregnancy outcome by suspending tocolysis in early labor (APOSTEL-I trial). BMC Pregnancy Childbirth 9:38

7. Wyatt SN, Rhoads SJ (2006) A primer on antenatal testing for neonatal nurses: part 1 . Tests used to predict preterm labor. Adv Neonatal Care 6:175-180

8. Carr DB, Smith K, Parsons L, Chansky K, Shields LE (2000) Ultrasonography for cervical length measurement: agreement between transvaginal and translabial techniques. Obstet Gynecol 96:554-558

9. Clement S, Candy B, Heath V, To M, Nicolaides KH (2003) Transvaginal ultrasound in pregnancy: its acceptability to women and maternal psychological morbidity. Ultrasound Obstet Gynecol 22:508-514

10. Heath VC, Southall TR, Souka AP, Novakov A, Nicolaides KH (1998) Cervical length at 23 weeks of gestation: relation to demographic characteristics and previous obstetric history. Ultrasound Obstet Gynecol 12:304-311

11. Hertzberg BS, Livingston E, DeLong DM, McNally PJ, Fazekas CK, Kliewer MA (2001) Ultrasonographic evaluation of the cervix: transperineal versus endovaginal imaging. J Ultrasound Med 20:1071-1078

12. Leitich H (2005) Secondary predictors of preterm labour. BJOG 112(Suppl 1):48-50

13. Sonek JD, Iams JD, Blumenfeld M, Johnson F, Landon M, Gabbe S (1990) Measurement of cervical length in pregnancy: comparison between vaginal ultrasonography and digital examination. Obstet Gynecol 76:172-175

14. Vidaeff AC, Ramin SM (2006) From concept to practice: the recent history of preterm delivery prevention. Part I: cervical competence. Am J Perinatol 23:3-13

15. Volumenie JL, Luton D, De SM, Sibony O, Blot P, Oury JF (2004) Ultrasonographic cervical length measurement is not a better predictor of preterm delivery than digital examination in a population of patients with idiopathic preterm labor. Eur J Obstet Gynecol Reprod Biol 117:33-37

16. Berghella V, Bega G, Tolosa JE, Berghella M (2003) Ultrasound assessment of the cervix. Clin Obstet Gynecol 46:947-962

17. Sanin-Blair J, Palacio M, Delgado J, Figueras F, Coll O, Cabero L, Cararach V, Gratacos E (2004) Impact of ultrasound cervical length assessment on duration of hospital stay in the clinical management of threatened preterm labor. Ultrasound Obstet Gynecol 24:756-760

18. Holst RM, Jacobsson B, Hagberg H, Wennerholm UB (2006) Cervical length in women in preterm labor with intact membranes: relationship to intra-amniotic inflammation/microbial invasion, cervical inflammation and preterm delivery. Ultrasound Obstet Gynecol 28:768-774

19. Berghella V, Ness A, Bega G, Berghella M (2005) Cervical sonography in women with symptoms of preterm labor. Obstet Gynecol Clin North Am 32:383-396

20. Chao AS, Chao A, Hsieh PC (2008) Ultrasound assessment of cervical length in pregnancy. Taiwan $\mathrm{J}$ Obstet Gynecol 47:291-295

21. Doyle NM, Monga M (2004) Role of ultrasound in screening patients at risk for preterm delivery. Obstet Gynecol Clin North Am 31:125-139

22. Gomez R, Romero R, Medina L, Nien JK, Chaiworapongsa T, Carstens M, Gonzalez R, Espinoza J, Iams JD, Edwin S, Rojas I (2005) Cervicovaginal fibronectin improves the prediction of preterm delivery based on sonographic cervical length in patients with preterm uterine contractions and intact membranes. Am J Obstet Gynecol 192:350-359

23. Owen J (2003) Evaluation of the cervix by ultrasound for the prediction of preterm birth. Clin Perinatol 30:735-755

24. Rozenberg P (2005) Repeat measurement of cervical length after successful tocolysis [Letter]. Obstet Gynecol 105:443-444

25. Shennan A, Jones B (2004) The cervix and prematurity: aetiology, prediction and prevention. Semin Fetal Neonatal Med 9:471-479

26. Vendittelli F, Volumenie J (2000) Transvaginal ultrasonography examination of the uterine cervix in hospitalised women undergoing preterm labour. Eur J Obstet Gynecol Reprod Biol 90:3-11

27. Vendittelli F, Mamelle N, Munoz F, Janky E (2001) Transvaginal ultrasonography of the uterine cervix in hospitalized women with preterm labor. Int J Gynaecol Obstet 72:117-125

28. Tan PC, Vallikkannu N, Suguna S, Quek KF, Hassan J (2007) Transvaginal sonographic measurement of cervical length vs. Bishop score in labor induction at term: tolerability and prediction of Cesarean delivery. Ultrasound Obstet Gynecol 29:568-573

29. Braithwaite JM, Economides DL (1997) Acceptability by patients of transvaginal sonography in the elective assessment of the firsttrimester fetus. Ultrasound Obstet Gynecol 9:91-93

30. Goffinet F, Maillard F, Fulla Y, Cabrol D (2001) Biochemical markers (without markers of infection) of the risk of preterm delivery. Implications for clinical practice. Eur J Obstet Gynecol Reprod Biol 94:59-68

31. Goldenberg RL, Culhane JF, Iams JD, Romero R (2008) Epidemiology and causes of preterm birth. Lancet 371:75-84 